\title{
Bioactive compounds extraction from malted quinoa using water-ethanol mixtures under subcritical conditions
}

\author{
Jesica R. Mufari ${ }^{\text {a,b,*, Andrea C. Rodríguez-Ruiz }}{ }^{\text {a,c }}$, Antonella E. Bergesse ${ }^{\text {a,d }}$, \\ Patricia P. Miranda-Villa ${ }^{\mathrm{a}, \mathrm{c}}$, Valeria Nepote ${ }^{\mathrm{a}, \mathrm{d}}$, Alexis R. Velez ${ }^{\mathrm{a}, \mathrm{c}}$ \\ ${ }^{a}$ Instituto de Ciencia y Tecnología de Los Alimentos (ICTA) - Universidad Nacional de Córdoba (UNC), Av. Vélez Sarsfield, 1611, Argentina \\ ${ }^{\mathrm{b}}$ Instituto de Investigaciones Biológicas y Tecnológicas (IIByT) - CONICET - UNC, Av. Vélez Sarsfield, 1611, Argentina \\ ${ }^{\mathrm{c}}$ Instituto de Investigación y Desarrollo en Ingeniería de Procesos y Química Aplicada (IPQA) - CONICET - UNC, Av. Vélez Sarsfield, 1611, Argentina \\ ${ }^{\mathrm{d}}$ Instituto Multidisciplinario de Biología Vegetal (IMBIV) - CONICET - UNC, Av. Vélez Sarsfield 299, Argentina
}

\section{A R T I C L E I N F O}

\section{Keywords:}

Subcritical fluid extraction

Bioactive compound

Antioxidant activity

Malted quinoa flour

\begin{abstract}
A B S T R A C T
The extraction of bioactive compounds from malted quinoa flour using different water/ethanol mixtures under subcritical conditions was performed, and two mathematical models to describe the extraction kinetics were compared. The variables evaluated were extraction temperature, solvent mass flow rate and solvent composition, and the best conditions were selected using a screening design. The extract with the highest antioxidant activity with 95\% inhibition of DPPH, $2084 \mathrm{mg} \mathrm{GAE} / 100 \mathrm{~g}$ flour of total phenol content (TPC), and $2029 \mathrm{mg}$ QCE/100 g flour of total flavonoid content (TFC) was obtained at $200{ }^{\circ} \mathrm{C}, 2.5 \mathrm{~g} / \mathrm{min}$ and $25 \%$ ethanol. For these conditions, the two-site kinetic model had a better fit. When comparing these results with conventional extraction techniques, the extraction yield and antioxidant capacity enhanced. Hence this technique results promising since it also allows to obtain extracts with an antioxidant activity similar to commercial antioxidants.
\end{abstract}

\section{Introduction}

In recent years, an increasing interest in functional foods has been developed, since they provide not only nutritional and energy benefits but also additional physiological advantages, such as antihypertensive, antioxidant or anti-inflammatory effects (Alkhatib et al., 2017). These products are generally traditional foods enriched with ingredients capable of providing or promoting a beneficial action for human health. Functional ingredients are commonly extracted from natural sources, such as cereals and legumes, spices, aromatic plants, industrial by-products like cocoa and olive or even algae and microalgae (Galanakis, 2018; Herrero, Cifuentes, \& Ibañez, 2006; Jokic, Gagic, Knez, Šubaric, \& Škerget, 2018).

Quinoa (Chenopodium quinoa Willd) is an ancestral grain that has gained popularity due to its nutritional properties (Abugoch James, 2009), not only because of the high protein, fatty acid and mineral content, but also because of the presence of several bioactive compounds, such as saponins, flavonoids, polyphenols and anthocyanins (Liu, 2019). Many studies have focused on these compounds, as well as their antioxidant activity, antimicrobial activity, and potential health-promoting and/or disease-preventive properties including anti-inflammatory, anti-cancer, and cardioprotective effects.

A method used to enhance the antioxidant capacity in cereals or pseudocereals is germination, an economical and effective process that also reduces antinutritional compounds while substantially increasing the bioavailability of micronutrients and improving the sensory properties of grains (Suárez-Estrella, Torri, Pagani, \& Marti, 2018). In recent years, investigations have evaluated the content and potential of antioxidants in germinated pseudocereals, establishing the optimal germination time in seeds of quinoa, amaranth, cañihua and buckwheat (Abderrahim et al., 2012; Niro et al. al., 2019). It has also been studied how germination in quinoa grains had a positive influence on the functional (Carciochi, Galván-D'Alessandro, Vandendriessche, \& Chollet, 2016; Atwaa et al., 2020), nutritional (Miranda-Villa, Mufari, Bergesse, \& Calandri, 2019; Alvarez-Jubete, Wijngaard, Arendt, \& Gallager, 2010), technological (Mäkinen, Zannini, \& Arendt, 2013) and sensory properties (Naga Sai Srujana, Anila Kumari, Uma Maheswari, Suneetha Devi, \& Jessie Suneetha, 2017; Suárez-Estrella et al., 2018) in

\footnotetext{
* Corresponding author. Instituto de Ciencia y Tecnología de los Alimentos (ICTA) - Universidad Nacional de Córdoba (UNC), Av. Vélez Sarsfield 1611, Córdoba, Argentina.

E-mail addresses: romi_mufari@hotmail.com (J.R. Mufari), carodruiz6@gmail.com (A.C. Rodríguez-Ruiz), abergesse@agro.unc.edu.ar (A.E. Bergesse), pmirandavilla@gmail.com (P.P. Miranda-Villa), avelez@unc.edu.ar (A.R. Velez).
} 
gluten-free food products.

One of the current challenges is the quantitative extraction of these bioactive compounds while maintaining their biological activity and chemical structure. This is a critical stage in order to correctly characterize them or to propose their incorporation as an ingredient in a functional food. The extraction techniques employed so far involve the use of organic solvents, which produce high extraction yields but have a low selectivity, resulting in an increase in time and cost of the process as subsequent purification stages may be required (Galanakis, 2012). In addition, the use of these solvents is prohibited for the food and pharmaceutical industry, due to their toxicity and residual effect. The solvents approved for extractions depend on the regulations of each country, although water and ethanol comply with the quality and safety requirements of products worldwide. However, it is not always possible to achieve high yields with traditional extraction processes under these conditions.

In this context, alternative extraction methods capable of overcoming the above-mentioned drawbacks are being studied: microwaveassisted extraction, ultrasound-assisted extraction, supercritical fluid extraction and subcritical fluids extraction. These extraction techniques provide higher extraction yields and selectivity, shorter extraction times (increased diffusion and extraction rates) and do not use toxic organic solvents (Herrero, Cifuentes, \& Ibáñez, 2006).

The subcritical extraction method uses mainly water or alcohol: water mixtures at temperatures above $100{ }^{\circ} \mathrm{C}$ and below $374{ }^{\circ} \mathrm{C}$ and at pressure above atmospheric (10-80 bar) to keep it in a liquid state, which provides particular characteristics to the solvent and emerges as a useful tool to replace traditional extraction methods. It is a green method and environmentally friendly, and a safe and fast extraction technique that achieves high extraction yields of medium and high polarity compounds contained in a solid matrix (Rodríguez-Meizoso et al., 2010).

Subcritical water could be an excellent alternative to extract all flavonoids and organic acids, including non-polar flavanones (M'hiri, Ioannou, Ghoul, \& Mihoubi-Boudhrioua, 2014). This extraction methodology has been reported in several investigations on different food matrices, such as rice (Hata, Wiboonsirikul, Maeda, Kimura, \& Adachi, 2008), pistachio (Bodoira et al., 2019), and peanut skins (Bodoira, Rossi, Montenegro, Maestri, \& Velez, 2017). Along with the extraction, stages of purification, total quantification of compounds, individual characterization and analysis of the impact on the chemical characteristics and biological activity of the extraction process should be designed (M'hiri et al., 2014). Each matrix presents a different profile of phenolic compounds and therefore a particular behavior against the extraction parameters, hence many research works focus on finding the appropriate conditions for each matrix from which the bioactive compounds are extracted (Yammine, Delsart, Vitrac, Peuchot, \& Ghidossi, 2020).

However, to our knowledge, there are no reports on the use of this methodology to extract antioxidant compounds from sprouted quinoa grains. Hence this study aims to evaluate the use of water:ethanol mixtures under subcritical conditions as an extraction technique and the effect of operating variables for the recovery of bioactive compounds from malted quinoa flour. These results can contribute to the selection of the optimal working conditions to obtain the highest extraction performance and the highest antioxidant activity in the extracts obtained from malted quinoa.

\section{Materials and methods}

\subsection{Plant material}

The quinoa seeds (Cica variety) were harvested in La Poma $\left(24^{\circ} 43^{\prime} 08^{\prime \prime}\right.$ South $66^{\circ} 12^{\prime} 00^{\prime \prime}$ West), Salta, Argentina, in 2016 . The grains were sieved to remove impurities and then stored in sealed polyethylene bags until use.

\subsection{Obtaining malted quinoa flour}

Quinoa seeds were washed and moisturized in distilled water (1:10 ratio), with agitation, for $2 \mathrm{~h}$ at $20{ }^{\circ} \mathrm{C}$ and then drained using a cloth filter. The controlled germination was carried out in a closed plastic container, inside which the grains were arranged in the form of a monolayer on a grid of the same material, for $24 \mathrm{~h}$, with a temperature of $25{ }^{\circ} \mathrm{C}$ and $60 \%$ relative humidity, protected from light. Finally, they were dried with hot air flow at $50{ }^{\circ} \mathrm{C}$ for approximately $30 \mathrm{~min}(11 \%$ humidity) and were ground in a hammer mill with $0.25 \mathrm{~mm}$ mesh to obtain the malted quinoa flour (MQF) (Miranda-Villa et al., 2019).

\subsection{Extraction procedure and optimization of working conditions}

The extraction was carried in an in-house developed apparatus according to the scheme shown in Supplementary Figure. It consists on a stainless-steel cell of $18.5 \mathrm{~mL}$ volume, equipped with an aluminum heating jacket and electrical resistances connected to a temperature controller, a HPLC type pump (ELDEX, model OPTOS 2SM, California, USA) for the regulation of the extraction solvent mass flow rate; a preheater with temperature control and a back-pressure regulator for pressure control. In order to maintain the temperature of the extraction cell, it was located in a thermally insulated box. Likewise, at the end of the equipment, the extracts were cooled down before decompression by means of 1/8-inch diameter stainless steel pipes immersed in a cold bath.

The extraction variables analyzed were temperature $\left(\mathrm{T}:{ }^{\circ} \mathrm{C}\right)$, extraction solvent mass flow rate (F: $\mathrm{g} / \mathrm{min}$ ) and extraction solvent composition (S: \% w/w ethanol). In order to know the effect of these variables on the extracts, an experimental screening design was applied in which each variable was evaluated independently, keeping the others at level 0 , as shown in Supplementary Table.

For each extraction, $3 \mathrm{~g}$ of MQF were loaded into a stainless steel cartridge that was later placed inside the extraction cell. Seven extract fractions were collected: the first three fractions corresponded to $30 \mathrm{~g}$ and the following four of $70 \mathrm{~g}$. A total of $370 \mathrm{~g}$ of extract for each combination of variables were collected. All extract fractions were stored in amber glass bottles and placed in freezer until further analysis. Each combination of variables (10 trials) was performed in duplicate.

In order to improve the extraction method, a final experimental run was carried out using the combination of the maximum extraction conditions of each independent variable (extract selected as optimal).

A conventional extraction by reflux using alcohol:water $75 \%(\mathrm{v} / \mathrm{v})$ as solvent, at $60{ }^{\circ} \mathrm{C}$ and atmospheric pressure for $1 \mathrm{~h}$ was also carried out.

\subsection{Chemical analysis of the extracts}

Total solid, phenols and flavonoid content, antioxidant capacity and melanoidin contents were determined in the extracts obtained in each experimental run and in the conventional extract.

The total solids content (TS) or dry matter was determined by technical gravimetry 934.01 (AOAC, 1999). For this purpose, approximately $5 \mathrm{~g}$ of extract were placed in a previously weighed crucible and placed in an oven at $105{ }^{\circ} \mathrm{C}$ to constant weight, recording the dry mass obtained.

The total phenol content (TPC) was determined using the FolinCiocalteu method in microplate (Leos-Rivas, Rivas-Morales, \& García-Hernández, 2016). For this purpose, $10 \mu \mathrm{L}$ of sample, $10 \mu \mathrm{L}$ of Folin reagent, $150 \mu \mathrm{L}$ of distilled water and $30 \mu \mathrm{L}$ of a saturated solution of sodium carbonate were placed. It was left to react in the dark for $1 \mathrm{~h}$ and the absorbance was determined at $765 \mathrm{~nm}$ in a UV-visible spectrophotometer (Spectrum SP-2100 UV-Visible, Zhejiang, China). A standard gallic acid (Sigma-Aldrich, Germany) curve was used to determine the total phenolic content. The results were expressed as mg GAE/ $100 \mathrm{~g}$ of dry matter.

The total flavonoid content (TFC) was determined using the $\mathrm{AlCl}_{3}$ 
microplate method (Larrauri, Zunino, Zygadlo, Grosso, \& Nepote, 2016). $150 \mu \mathrm{L}$ of sample and $150 \mu \mathrm{L}$ of $\mathrm{AlCl}_{3}$ (2\%, in ethanol) were placed in the microplate. It was left to react for $15 \mathrm{~min}$ and the absorbance was determined at $367 \mathrm{~nm}$ in a UV-visible spectrophotometer (Spectrum SP-2100 UV-Visible, Zhejiang, China). Calibration curves were made with a quercetin standard (Sigma-Aldrich, Germany). The results were expressed as mg QCE/ $100 \mathrm{~g}$ dry matter.

The radical scavenging capacity (RSC) of the first extracts obtained for each condition (initial $30 \mathrm{~g}$ ), was determined using the 2,2-dyphenil1-picryl hydrazyl radical (DPPH ${ }^{\circ}$ ) (Larrauri et al., 2016). $10 \mu \mathrm{L}$ of sample, $150 \mu \mathrm{L}$ of DPPH-methanolic solution $(40 \mu \mathrm{g} / \mathrm{mL})$ were added. The absorbance was measured after $30 \mathrm{~min}$ at $517 \mathrm{~nm}$ in a spectrophotometer (Spectro SP-2100 UV-Visible, Zhejiang, China). Radical scavenging capacity was calculated by the following equation:

$\% R S C=\frac{1-(\text { Abs DPPH. }- \text { Abs muestra })}{A b s \text { DPPH. }} \times 100$

where Abs: Absorbance.

Different concentrations of each extract were measured, following the methodology described above. Calibration curves were constructed, extract concentration ( $\mu$ g extract $/ \mathrm{mL}$ ) vs. $\%$ RSC. $\mathrm{IC}_{50}$ was defined as the extract concentration at which the RSC is $50 \%$. A low $\mathrm{IC}_{50}$ value corresponds to high antioxidant activity.

Melanoidin contents were qualitatively determined, estimated by means of browning intensity of the extracted samples. For this purpose, the absorption of the extracts was measured at $420 \mathrm{~nm}$, using a microplate spectrophotometer (BMG Labtech $\mathrm{GmbH}$, Germany).

All extractions in section 2.3 were performed in duplicate and each determination was performed in triplicate $(n=6)$.

\subsection{Antioxidant activity of the extract selected as optimal}

The analyses were performed on the first fraction of the seven collected. Each of the chemical determinations described above (TPC, TFC and DPPH assay) were analyzed. Further antioxidant activity assays were performed in order to evaluate the behavior of the extract considered as optimal against different antioxidant mechanisms of action: Trolox Equivalent Antioxidant Capacity (TEAC), Ferric Reducing Antioxidant Power (FRAP) and Oxygen Radical Absorbance Capacity (ORAC), and an accelerated oxidation test performed by Rancimat.

TEAC assay: $990 \mu \mathrm{L}$ of ABTS (2,2'-Azino-bis (3-ethylbenzothiazoline6-sulfonic acid)) reagent (Sigma ${ }^{\circledR}$, St. Louis, USA) diluted in ethanol $95 \%$ (Abs $0.7 \pm 0.02$ ) was mixed with $10 \mu \mathrm{L}$ of extract, and a standard Trolox (Sigma ${ }^{\circledR}$, St. Louis, USA). The absorbance was measured after 25 min at $734 \mathrm{~nm}$ in a spectrophotometer (Spectro SP-2100 UV-Visible, Zhejiang, China). All measurements were conducted in triplicate and the results were expressed as mmol of Trolox equivalents/g of dry extract (Re et al., 1999).

FRAP assay: $10 \mu \mathrm{L}$ of extract, or distilled water as blank, and $990 \mu \mathrm{L}$ of FRAP reagent (ferric chloride and TPTZ (2,4,6-Tris (2-pyridyl)-striazine) in acetate buffer ( $\mathrm{pH} 3.6)$ ) were placed in a reaction tube. The absorbance was measured after $5 \mathrm{~min}$ at $593 \mathrm{~nm}$ in a spectrophotometer Spectro SP-2100 UV-Visible, Zhejiang, China). A calibration curve with ascorbic acid (Biopack, Buenos Aires, Argentina) was used. All measurements were conducted in triplicate. The results were expressed as $\mathrm{mg}$ of ascorbic acid equivalents/g of dry extract (Benzie \& Strain, 1996).

$O_{R A C}$ assay: this assay was carried out according to Plaza, Amigo-Benavent, del Castillo, Ibáñez, and Herrero (2010) with slight modifications. Briefly, $100 \mu \mathrm{L}$ of sample (with a concentration between 50 and $100 \mu \mathrm{g}$ d.m. $/ \mathrm{mL}), 125 \mu \mathrm{L}$ of fluorescein $(2 \mu \mathrm{M}$ in $30 \mathrm{mM}$ phosphate buffer, $\mathrm{pH} 7.5$ ), the oxidation reaction was initiated by adding $100 \mu \mathrm{L}$ of AAPH (2,2'-azobis(2-amidino-propane) dihydrochloride) solution in a concentration of $590 \mathrm{mM}$. The fluorescence readings were recorded at $\lambda$ exc $=493 \mathrm{~nm}$ and $\lambda \mathrm{em}=515 \mathrm{~nm}$ every $5 \mathrm{~min}$ for $1 \mathrm{~h}$, at $37^{\circ} \mathrm{C}$ in a fluorometer (Synergy HT microplate reader, BioTek, Vermont,
United States). A blank was also analyzed in each run, calibration curves of Trolox were constructed and employed for quantification of the antioxidant capacity against peroxyl radicals. Normalized antioxidant curves (fluorescence versus time) were obtained and the area under the fluorescence decay curve (AUC) was calculated. Regression equations between net AUC and antioxidant concentration were obtained and employed for calculation of the $\mathrm{ORAC}_{\mathrm{FL}}$ values that were expressed as $\mathrm{mg}$ of Trolox equivalents/g of dry extract.

Rancimat analysis: the accelerated oxidation was determined using a Rancimat (Metrohm Model 743, Switzerland) equipment, under the following conditions: $100{ }^{\circ} \mathrm{C}$ and air flow of $20 \mathrm{~L} / \mathrm{h}$ and. The extract was mixed with $2.5 \mathrm{~g}$ of degummed crude soybean oil provided by Trisoil S. A., at a concentration of $2000 \mathrm{ppm}$. The result was compared with soybean oil added with $200 \mathrm{ppm}$ of BHT (Fluka, Sigma-Aldrich, St. Luois, USA). A control sample was also oxidized under the same conditions. The samples were analyzed according to Quiroga, Riveros, Zygadlo, Grosso, and Nepote (2011).

\subsection{Statistical analysis}

The results are expressed as mean \pm standard deviation of the replications. Data analysis was performed using InfoStat ${ }^{\circledR}$ professional version 2014 (InfoStat Group, FCA, National University of Córdoba, Argentina). The differences between the determinations were estimated using an analysis of variance (ANAVA). In those cases, where statistically significant differences were observed ( $\alpha=0.05$ ), a multiple comparison test was subsequently applied (DGC, DiRienzo, Guzmán and Casanoves).

\subsection{Extraction kinetic models}

To describe the extraction of the compounds of interest (total phenols and flavonoids) obtained under optimal conditions, two kinetic models were compared, known as one-site and two-site kinetic desorption models (Anekpankul, Goto, Sasaki, Pavasant, \& Shotipruk, 2007).

The one-site kinetic model considers that initially the solute is uniformly distributed within the matrix, and that extraction is controlled by intraparticular diffusion. The mathematical expression for calculating the total mass of extracted solute $(\mathrm{mt})$ is as follows:

$\frac{m_{t}}{m_{0}}=1-\exp (-k t)$

where $m_{0}$ is the initial mass of solute in the plant matrix, $k$ is the first order velocity constant and $t$ is time.

The two-site kinetic model is a modification of the one-site model, and it considers that in plant matrices the compounds of interest are contained within cells. When the plant matrix is mechanically ground some of these cells are broken while others remain intact, so there is a part of the solute, known as free solute, which is more easily extracted since it was the one inside the damaged cells and is in direct contact with the solvent. On the other hand, the remaining solute fraction, known as bound solute, is found inside the cells that remain intact and is more difficult to extract due to the high mass transfer resistance that exists from inside the particle. According to the above, the two-site kinetic model is described by the following equation:

$$
\frac{m_{t}}{m_{0}}=1-f \exp \left(-k_{1} t\right)-(1-f) \exp \left(-k_{2} t\right)
$$

where $f$ is the fraction of solute that drains at a higher velocity defined by the first order constant $k_{1}$, and (1-f) is the remaining fraction that drains at a lower velocity, given by the first order constant $k_{2}$, where $t$ is the time.

The kinetic parameters of both kinetic models were obtained by adjusting the extraction curve under optimal conditions using Microsoft Excel Solver ${ }^{\circledR}$, minimizing the "root mean square error (RMSE)" 
function:

$$
R M S E=\sqrt{\sum_{i=1}^{n} \frac{\left[\left(m_{i} / m_{0}\right)_{\exp }-\left(m_{i} / m_{0}\right)_{\text {model }}\right]^{2}}{n}}
$$

where $m_{i}$ is the mass of analyte extracted in time " $\mathrm{t}$ " and " $\mathrm{n}$ " is the total number of samples analyzed.

To select the model that best predicts the extraction of the compounds of interest, the fit of each model was evaluated by comparing the average absolute relative deviation (AARD\%) between the experimental and predicted yields:

$$
(A A R D \%)=\frac{1}{n} \sum_{i=1}^{n} \frac{\left|\left(m_{i} / m_{0}\right)_{\exp }-\left(m_{i} / m_{0}\right)_{\text {model }}\right|}{\left(m_{i} / m_{0}\right)_{\exp }} \times 100
$$

\section{Results and discussion}

As mentioned above, different extraction conditions have been studied using subcritical fluids to obtain compounds with antioxidant activity contained in MQF. The extraction yield, the total phenol and flavonoid content and the antioxidant activity obtained for each combination of variables are very important when defining the best extraction conditions. Although there are many studies on the extraction of antioxidant compounds under subcritical conditions, the extraction yields are very sensitive to the characteristics of the matrix and the type of compounds that each matrix contains (Yammine et al., 2020).

Performing a statistical analysis by response variable and considering all the conditions tested (Table 1), significant differences are evident in all treatments for each of the responses studied.

Table 1

\begin{tabular}{|c|c|c|c|c|c|}
\hline $\begin{array}{l}\text { Variable } \\
\text { combinations }\end{array}$ & $\begin{array}{l}\text { Extraction } \\
\text { Yield (g dry } \\
\text { extract/100 } \\
\text { g MQF) }\end{array}$ & $\begin{array}{l}\text { TS }(\mathrm{g} \text { dry } \\
\text { extract/ } \\
100 \mathrm{~g} \\
\text { extract) }\end{array}$ & $\begin{array}{l}\text { TPC (mg } \\
\text { GAE/ } \\
100 \mathrm{~g} \\
\text { dry } \\
\text { matter) }\end{array}$ & $\begin{array}{l}\text { TFC (mg } \\
\text { QCE/ } \\
100 \mathrm{~g} \\
\text { dry } \\
\text { matter) }\end{array}$ & $\begin{array}{l}\text { DPPH } \\
\mathrm{IC}_{50}(\mu \mathrm{g} \\
\text { extract/ } \\
\mathrm{mL})\end{array}$ \\
\hline F0/T0/S0 & $64.3 e \pm 0.3$ & $\begin{array}{l}1.67 \mathrm{e} \pm \\
0.02\end{array}$ & $474 d \pm 4$ & $766 c \pm 2$ & $\begin{array}{l}1450.5 h \\
\pm 0.7\end{array}$ \\
\hline $\mathrm{F} 1 / \mathrm{T} 0 / \mathrm{S} 0$ & $51.7 \mathrm{c} \pm 0.3$ & $\begin{array}{l}1.54 d \pm \\
0.02\end{array}$ & $335 b \pm 9$ & $666 b \pm 6$ & $\begin{array}{l}1604.0 \mathrm{i} \\
\pm 0.2\end{array}$ \\
\hline $\mathrm{F} 2 / \mathrm{T} 0 / \mathrm{S} 0$ & $54.4 \mathrm{~d} \pm 0.4$ & $\begin{array}{l}1.33 c \pm \\
0.01\end{array}$ & $\begin{array}{l}357 \mathrm{c} \pm \\
10\end{array}$ & $650 a \pm 7$ & $\begin{array}{l}2660.3 \mathrm{j} \\
\pm 0.4\end{array}$ \\
\hline $\mathrm{T} 1 / \mathrm{F} 0 / \mathrm{S} 0$ & $77.5 h \pm 0.3$ & $\begin{array}{l}2.27 g \pm \\
0.03\end{array}$ & $\begin{array}{l}830 h \pm \\
10\end{array}$ & $999 e \pm 5$ & $\begin{array}{l}242.6 \mathrm{~d} \pm \\
0.7\end{array}$ \\
\hline $\mathrm{T} 2 / \mathrm{F} 0 / \mathrm{S} 0$ & $87.6 i \pm 0.1$ & $\begin{array}{l}2.73 h \pm \\
0.01\end{array}$ & $800 \mathrm{~g} \pm 4$ & $\begin{array}{l}1291 \mathrm{~h} \pm \\
2\end{array}$ & $\begin{array}{l}109.8 b \pm \\
0.9\end{array}$ \\
\hline T3/F0/S0 & $75.2 \mathrm{~g} \pm 0.5$ & $\begin{array}{l}2.33 g \pm \\
0.01\end{array}$ & $\begin{array}{l}1168 \mathrm{i} \pm \\
7\end{array}$ & $\begin{array}{l}1713 i \pm \\
5\end{array}$ & $\begin{array}{l}96.3 \mathrm{a} \\
\pm 0.4\end{array}$ \\
\hline $\mathrm{S} 1 / \mathrm{F} 0 / \mathrm{T} 0$ & $70.5 f \pm 0.1$ & $\begin{array}{l}2.11 \mathrm{f} \pm \\
0.03\end{array}$ & $807 g \pm 8$ & $\begin{array}{l}1155 g \pm \\
6\end{array}$ & $\begin{array}{l}260.9 c \pm \\
0.6\end{array}$ \\
\hline $\mathrm{S} 2 / \mathrm{F} 0 / \mathrm{T} 0$ & $16.9 b \pm 0.1$ & $\begin{array}{l}0.54 \mathrm{~b} \pm \\
0.02\end{array}$ & $279 a \pm 8$ & $\begin{array}{l}1022 \mathrm{f} \pm \\
6\end{array}$ & $\begin{array}{l}1090.4 \mathrm{~g} \\
\pm 0.5\end{array}$ \\
\hline S3/F0/T0 & $16.8 \mathrm{~b} \pm 0.1$ & $\begin{array}{l}0.53 \mathrm{~b} \pm \\
0.01\end{array}$ & $608 \mathrm{e} \pm 5$ & $\begin{array}{l}1024 \mathrm{f} \pm \\
4\end{array}$ & $\begin{array}{l}264.9 \mathrm{e} \pm \\
0.2\end{array}$ \\
\hline S4/F0/T0 & $9.8 \mathrm{a} \pm 0.2$ & $\begin{array}{l}0.32 \mathrm{a} \\
\pm 0.01\end{array}$ & $660 f \pm 9$ & $842 d \pm 4$ & $\begin{array}{l}448.4 \mathrm{f} \pm \\
0.6\end{array}$ \\
\hline $\mathrm{F} 0 / \mathrm{T} 3 / \mathrm{S} 1$ & $73.2 \pm 0.3$ & $\begin{array}{l}2.04 \pm \\
0.02\end{array}$ & $\begin{array}{l}2084 \pm \\
11\end{array}$ & $2029 \pm 2$ & $\begin{array}{l}29.6 \pm \\
0.4\end{array}$ \\
\hline Conventional & $50.1 \pm 0.5$ & $\begin{array}{l}1.04 \pm \\
0.04\end{array}$ & $837 \pm 9$ & $196 \pm 7$ & $\begin{array}{l}3025.1 \pm \\
0.6\end{array}$ \\
\hline
\end{tabular}

Extraction yield, composition and antioxidant activity of the different extracts

The accumulated mass values for the 7 extracts are presented, mean \pm standard deviation are reported for each combination of variables $(n=6)$. Different letters in the same column, denote statistically significant differences (ANOVA, Test DGC, $\mathrm{p}<0.05)$. T: temperature, ${ }^{\circ} \mathrm{C}$ (T0:140, T1:160, T2:180, T3:200), F: solvent mass flow rate, g/min (F0:2.5, F1: 5, F2: 7.5), S: solvent mixture composition, \% ethanol w/w (S0: 0, S1: 25, S2: 50, S3: 75, S4: 100), TS: total solids content, TPC: total phenolic content, TFC: total flavonoid content, DPPH $\mathrm{IC}_{50}$ : extract concentration at which the radical scavenging capacity is $50 \%$.
The extraction yields were very variable, in a range between 10 y 87 $\mathrm{g}$ dry extract/100 $\mathrm{g}$ of MQF, TPC between 279 and $1178 \mathrm{mg} \mathrm{GAE} / 100 \mathrm{~g}$ dry matter, TFC between 650 and $1713 \mathrm{mg}$ QCE/ $100 \mathrm{~g}$ dry matter and $\mathrm{IC}_{50}$ among 96 and $2660 \mu \mathrm{g}$ extract/mL.

When analyzing the behavior trend of mass flow rate (Fig. 1), increases are observed for all response variables studied. However, when observing the final extraction values in Table 1 , a significant raise in TS and $\mathrm{IC}_{50}$ at $2.5 \mathrm{~g} / \mathrm{min}$ could be detected; while no significant differences were found between TPC and TFC at any of the extraction solvent flows used.

Another variable evaluated was temperature (Fig. 2). This is the most important parameter to optimize in a subcritical extraction in the presence of water, because the physicochemical properties of the latter change with increasing temperature and this affects the extraction efficiency (Gilbert-López, Plaza, Mendiola, Ibáñez, \& Herrero, 2017). As the temperature increases, the dielectric constant of water and its polarity decreases, favoring the solubilization of non-polar compounds such as polyphenols (Yan et al., 2020).

Polyphenols in plant matrices are usually linked to polysaccharides or proteins. As the temperature increases, these interactions are broken, leaving the polyphenols free, which facilitates their extraction. In addition, there is thermal damage to the cell walls which allows for better diffusion of the extracting solvent. Both effects produce an increase in the mass transfer coefficient, increasing the extraction of the compounds of interest (Gong, Zhang, He, Yan, Yuan \& Gao, 2015).

The increase in extraction temperature resulted in a subsequent raise of TS, TPC and TFCs over $150 \%$ at $200{ }^{\circ} \mathrm{C}$ compared to lower extraction temperature $\left(140{ }^{\circ} \mathrm{C}\right)$. However, specifically, TS content was higher at $180^{\circ} \mathrm{C}$, an increase in temperature above this value reduced the number of dissolved solids, since other co-extracted components of the matrix (amino acids, proteins, sugars and starch) are likely to be degraded, thus reducing their solubility in the extractive medium or causing gas loss during this degradation.

Most of the studies carried out in extraction with water in subcritical conditions highlight temperature as the key factor for increasing the extraction of antioxidant compounds, establishing between 200 and $220{ }^{\circ} \mathrm{C}$ as optimal temperatures, similar to the one found in this study. For instance, grape pomace by-products (Duba, Casazza, Mohamed, Perego, \& Fiori, 2015), coriander seeds (Zeković et al., 2014), wild garlic (Tomšik et al., 2017) and Phlomis umbrosa Turcz (Ko, Lee, Nam, \& Chung, 2017) were subjected to $200{ }^{\circ} \mathrm{C}$; and pistachio nuts (Bodoira et al., 2019), sesame defatted seeds (Bodoira, Velez, Andreatta, Martínez, \& Maestri, 2017). and peanut skins (Bodoira, Rossi, et al., 2017) were extracted at $220^{\circ} \mathrm{C}$. Other authors report extraction temperatures below $120^{\circ} \mathrm{C}$, to avoid degradation and polymerization of polyphenolic compounds and caramelization reactions that can occur at temperatures above $160{ }^{\circ} \mathrm{C}$ (Gong et al., 2015). As stated before, the optimal extraction temperature of bioactive compounds is highly dependent on the differences in the plant matrix and the extraction system.

In terms of extraction solvent composition, the addition of $25 \%$ ethanol generated the highest extraction of compounds TS, TPC and TFC, with markedly higher values compared to other compositions in the solvent mixture (Fig. 3). This indicates the presence of polar compounds and a fraction of compounds of lower polarity. However, phenolic compounds did not show the same trend. The addition of $25 \%$ ethanol produces a significant increase in the extraction of these compounds, marking a maximum for the studied conditions. Increasing the proportion of ethanol to $50 \%$ leads to a minimum recovery of these compounds, which then increases to a practically similar value for a solvent containing $75 \%$ ethanol and for pure ethanol.

The flavonoid extraction yield presents a great increase when adding $25 \%$ of ethanol, reaching a maximum in the studied conditions. When using 50\%, 75\% and pure ethanol, the extraction yield of these compounds presents similar values, always above the yield of extraction with water, indicating the presence of compounds of average polarity. The addition of ethanol, modifies the dielectric constant and polarity of 

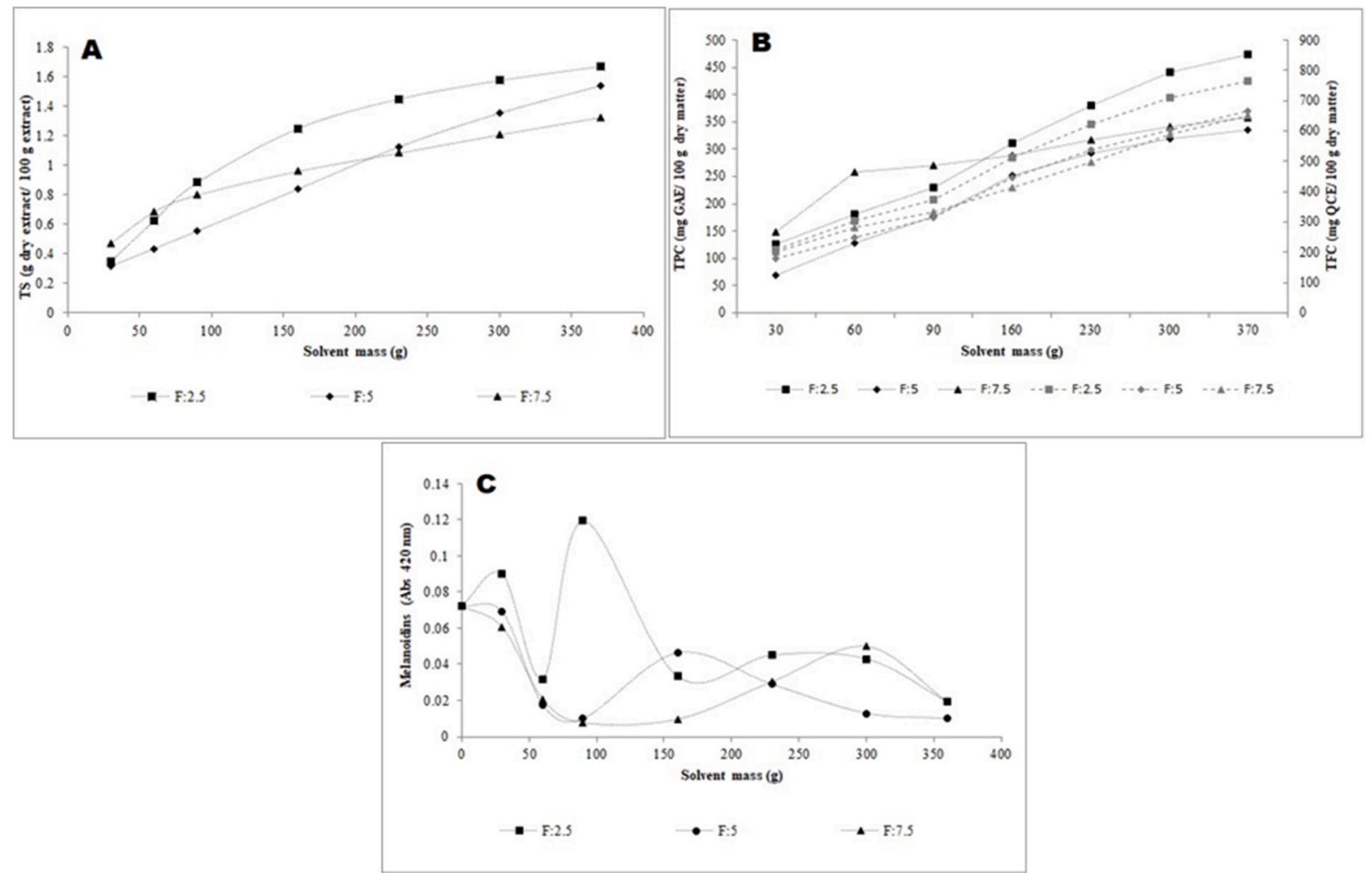

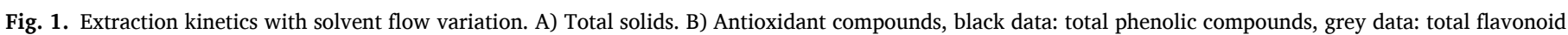
compounds. C) Melanoidins.
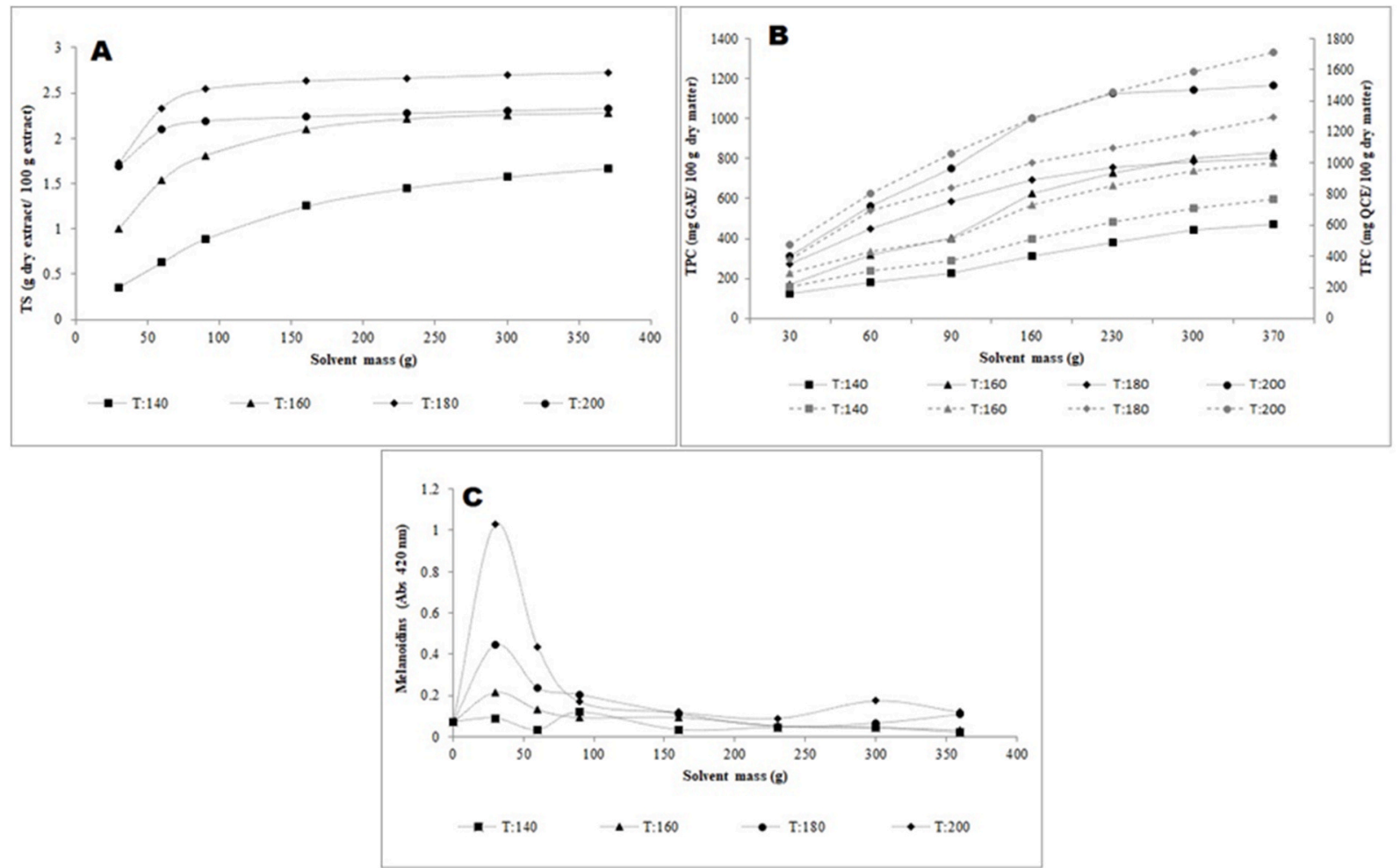

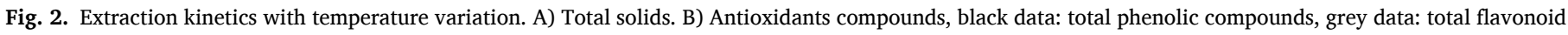
compounds. C) Melanoidins. 


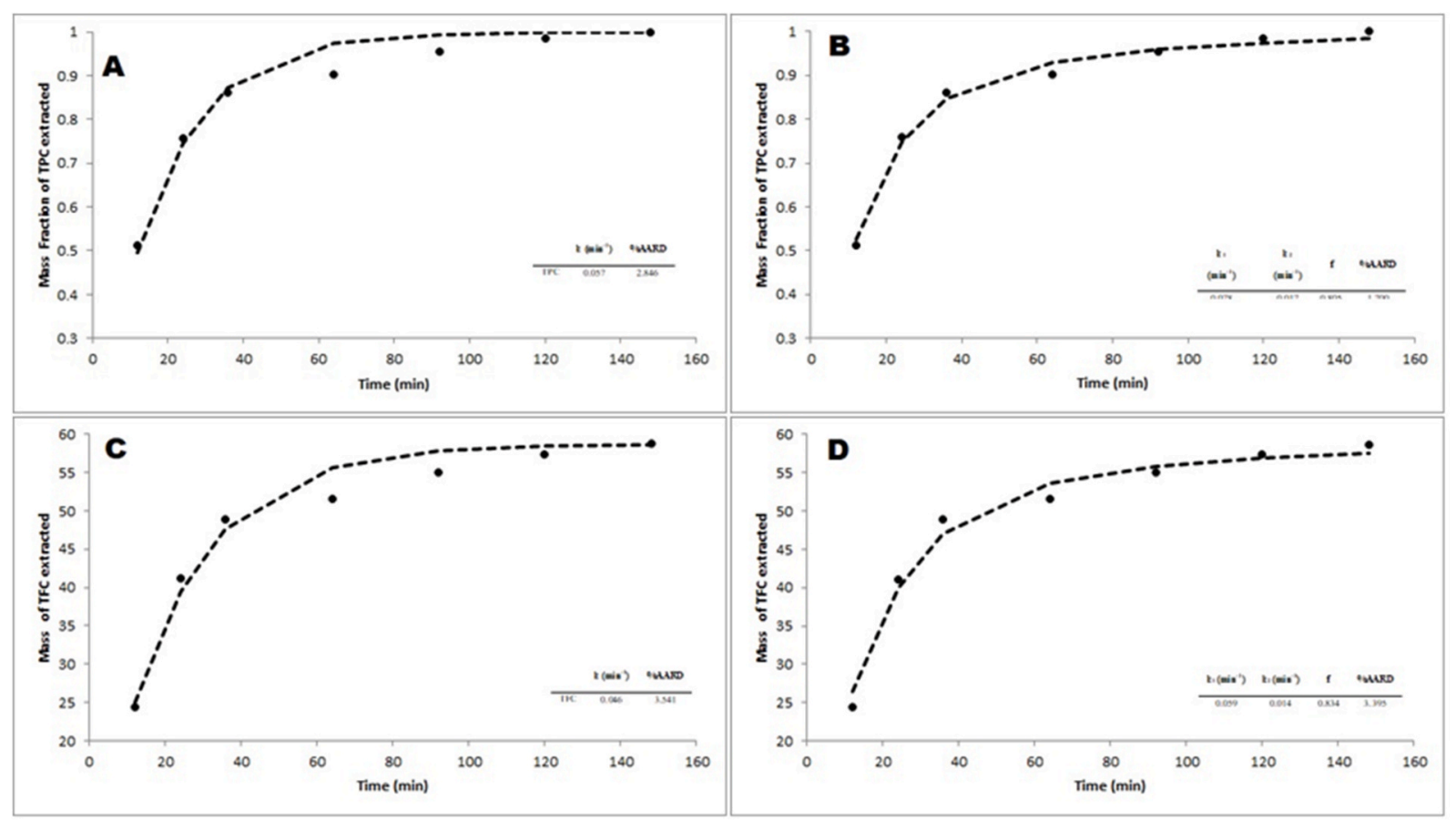

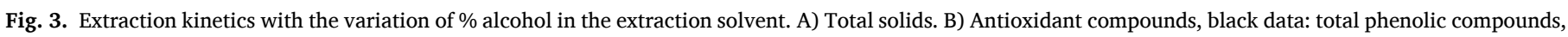
grey data: total flavonoid compounds. C) Melanoidins.

the extraction solvent, which favors the extraction of a greater variety of biological compounds (Bodoira, Rossi, et al., 2017). As it is a complex matrix, it presents different antioxidants with varied physicochemical properties that in this case we grouped in two families (phenols and flavonoids), which is why they do not follow a trend of solubility in homogeneous working conditions and an integral behavior is described given the variation of the parameters under study.

The formation of brown pigments in the extracted solutions is an effective method to detect the occurrence of non-enzymatic browning reactions, including Maillard's and caramelization reactions (Plaza et al., 2010). In Figs. 1-3, the behavior observed during extractions under different conditions is presented.

As can be noted, the lower the mass flow rate, the longer the contact time between the sample and the solvent, thus favoring non-enzymatic browning reactions. As time passes, the absorbance units decrease because the concentration of all the extracted compounds is lower. However, a marked increase in brown coloring is observed after $40 \mathrm{~min}$ of extraction, probably during the first few minutes the cell matrix breaks down, proteins are denatured and amino acids and simple sugars are released, which then give rise to the non-enzymatic browning reactions.

As far as temperature is concerned, these reactions are favored at high temperatures (above $140{ }^{\circ} \mathrm{C}$ ) because they are endothermic reactions (Hodge, 1953), so the higher the temperature the greater the formation of pigments, which in turn decrease in intensity by dilution of the pigments over time. Finally, the presence of $100 \%$ alcohol generates a higher initial intensity, probably due to the fact that water is a reaction product and its absence in the environment generates a displacement of the equilibrium towards the formation of products (Hodge, 1953). Also, alcohol at high temperature favors the dissolution of sugars and protein denaturation, which increases the availability of these products for Maillard's reactions to occur. In water, an increase in coloration is observed after $40 \mathrm{~min}$ of extraction, a behavior already described above.

Another aspect to highlight is that the formation of neo-antioxidants derived from Maillard's reactions and caramelization during extraction with subcritical water extraction has been proven (Gilbert-López et al., 2017; Plaza et al., 2010), which has an influence on the general antioxidant activity of the natural extracts obtained.

According to the analysis carried out previously, it was found that the conditions of maximum general extraction of antioxidant compounds (without interaction between variables) correspond to $\mathrm{F}: 2.5 \mathrm{~g} /$ min, T: $200{ }^{\circ} \mathrm{C}$ and S: $25 \% \mathrm{w} / \mathrm{w}$ of ethanol. Under these conditions, it was possible to obtain an extract considered to be optimal.

A new extraction was carried out combining these conditions, obtaining significant increases in TPC, TFC and $\mathrm{IC}_{50}$, although the phenolic compounds were those that presented the greatest impact. The extraction yield and TS were lower, indicating that the extract was further enriched in the compounds of interest (Table 1).

The extraction kinetics of TPC and TFC were favored at all times (Fig. 4), though the highest extraction rate occurred in the first $40 \mathrm{~min}$ approximately.

When comparing the values obtained when extracting under conventional conditions with those obtained by subcritical fluids, a very marked increase in the extraction capacity of phenolic compounds and flavonoids is observed, with the consequent increase in the antioxidant capacity of these extracts (Table 1). This behavior is observed since water in subcritical conditions reaches higher temperatures and lower polarity, facilitating the dissolution of the compounds of interest. In addition, water has lower viscosity and surface tension which increases the molecular diffusion speed (Yan et al., 2020).

Although there are no similar studies in the literature applying subcritical water extraction techniques in MQF, the optimization of the extraction of antioxidant compounds by means of ultrasound-assisted extraction has been studied, finding that the most influential variables are temperature and alcohol content in the extracting solvent. Carciochi (2014) reported that the best extraction yields were found at the highest working temperature $\left(60^{\circ} \mathrm{C}\right)$ and using $80 \%$ of alcohol. Another aspect to highlight is that the author also reports increases in TPC, TFC and the formation of non-enzymatic browning products during the thermal treatment of the MQF (between 100 and $190{ }^{\circ} \mathrm{C}$ ) (Carciochi, 2014).

In order to evaluate the free radical scavenging capacity of the extract obtained under optimal conditions with assays based on the electron transfer (ET) and hydrogen atom transfer mechanisms (HAT), the DPPH, TEAC and FRAP (ET) and ORAC (HAT) assays were 


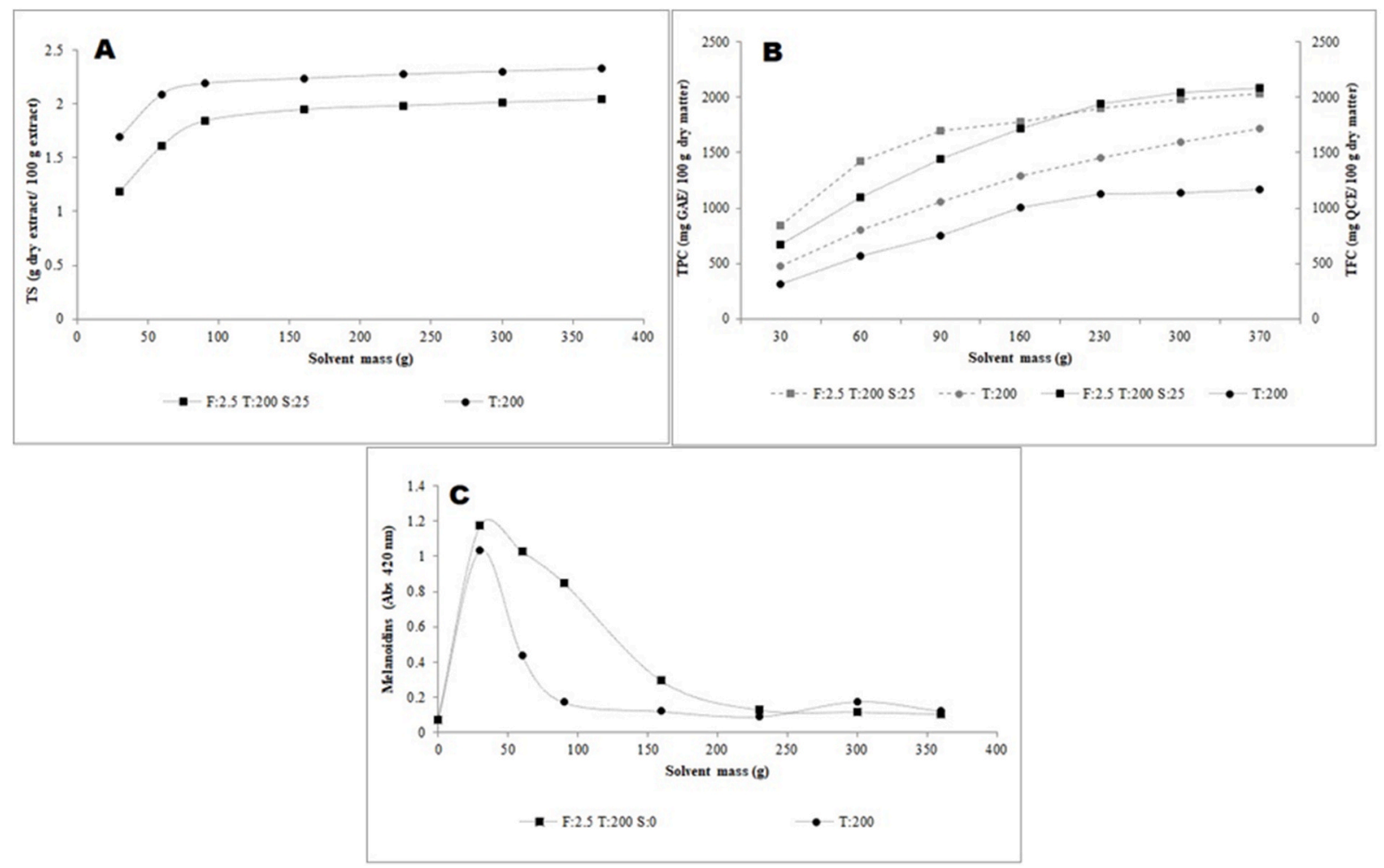

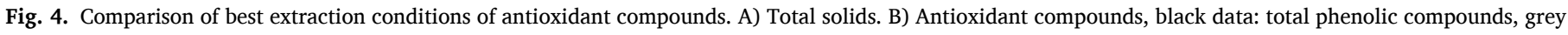
data: total flavonoid compounds. C) Melanoidins.

performed.

The extract presented a high scavenging capacity of $\mathrm{DPPH}^{\bullet}\left(\mathrm{IC}_{50}\right)$ and $\mathrm{ABTS}^{\bullet+}$ radicals $(29.6 \pm 0.4 \mu \mathrm{g} / \mathrm{mL}$ and $231.5 \pm 0.2 \mu \mathrm{mol} / \mathrm{g}$ dry matter, respectively) compared to the values reported for different quinoa grain extracts. Nickel, Spanier, Botelho, Gularte, and Helbig (2016) described that quinoa grains samples subjected to various types of processing required from 2711 to $6178 \mu \mathrm{g} / \mathrm{mL}$ to inhibit $50 \%$ of DPPH radicals $\left(\mathrm{IC}_{50}\right)$. Regarding TEAC assay, Sobota, Świeca, Gęsiński, Wirkijowska, and Bochnak (2020) reported ranges from 0.99 to $8.71 \mu \mathrm{mol}$ TE/g dry matter, Escribano et al. (2017) between 6 and $47.4 \mu \mathrm{mol} \mathrm{TE} / \mathrm{g}$ dry matter and Laus, Gagliardi, Soccio, Flagella, and Pastore (2012) ranges from 0.33 to $12.8 \mu \mathrm{mol} \mathrm{TE} / \mathrm{g}$ dry matter. In turn, the extract displayed power to reduce ferric ions measured by the FRAP technique (39 $\pm 4 \mathrm{mg}$ ascorbic acid eq./g dry extract). Other authors (Escribano et al., 2017; Nickel et al., 2016) reported high values of this activity but using different standards and expressing the results in different units of measurement, making numerical comparisons difficult. The ORAC protocol showed an antioxidant activity value $(28.2 \pm 0.9 \mathrm{mg}$ Trolox eq./g dry extract) about 3-fold higher than that hydrophilic extract of quinoa grains reported by Laus et al. (2012). All of these differences found in the results of antioxidant assays with respect to literature may be due to improvements in the extraction method, as well as to changes produced during the germination process and the genotype of grain used.

The effect of the extract of germinated quinoa and BHT (synthetic antioxidant) enrichment on the oxidative stability of crude soybean oil was evaluated by Rancimat equipment. The induction time (h) was used as an indicator of the antioxidative potential of added antioxidants. The control sample displayed the lowest induction time (12.3 $\pm 0.5 \mathrm{~h})$, followed by the quinoa extract and the BHT samples, with no significant differences $(p>0.05)$ between them $(13.20 \pm 0.03 \mathrm{~h}$ and $13.4 \pm 0.2 \mathrm{~h}$, respectively). This means that under the described working conditions, the quinoa extract was found to be effective in stabilizing soybean oil against oxidative deterioration, compared to a control sample. Atwaa and El-Araby (2020) extracted antioxidant compounds from quinoa grains by a conventional method and reported an induction time of 12.7 $\mathrm{h}$ when adding the extract to fermented cream analogue (concentration of $200 \mathrm{ppm}$ ). The use of numerous assays based on different mechanisms, firmly support the bioactive potential of the germinated grain.

\subsection{Kinetic model}

After the extraction in optimal conditions, the cumulative values of TPC and TFC were considered as $m_{t}$ (Table 1 ). As shown in Fig. 5, both models can predict the experimental data with good accuracy, which is quantified and compared using AARD (\%). However, according to the kinetic parameters and goodness-of-fit reported in Fig. 5, the two-site kinetic model presents a better fit. This model includes a fast and a slow rate constant of the extracted fractions, named $k 1$ and $k 2$, related to the partition coefficients and the characteristics of the matrix (effective diffusivity), respectively. The model is simple and provides useful information practical for scale up and designing subcritical water extraction processes (Duba et al., 2015).

The minor differences between the predictions of the two models can be attributed to the high estimated value of the fraction of easily desorbed solute ( $\mathrm{f}=0.805$ and 0.834 , for TPC and TFC, respectively), indicating that the predominance of rapidly desorbed solute.

In previous studies, the two-site kinetic model is applied for the extraction of polyphenols from wine by-products, with good results. The model is simple and provides useful information for process design at the industrial level (Duba et al., 2015).

\section{Conclusion}

A significant effect on the extraction of the antioxidant compounds was observed when the working conditions varied; an improvement in the extracts was noted when lower mass flow rates of extraction solvent were used, which favored longer contact times between the solvent and 

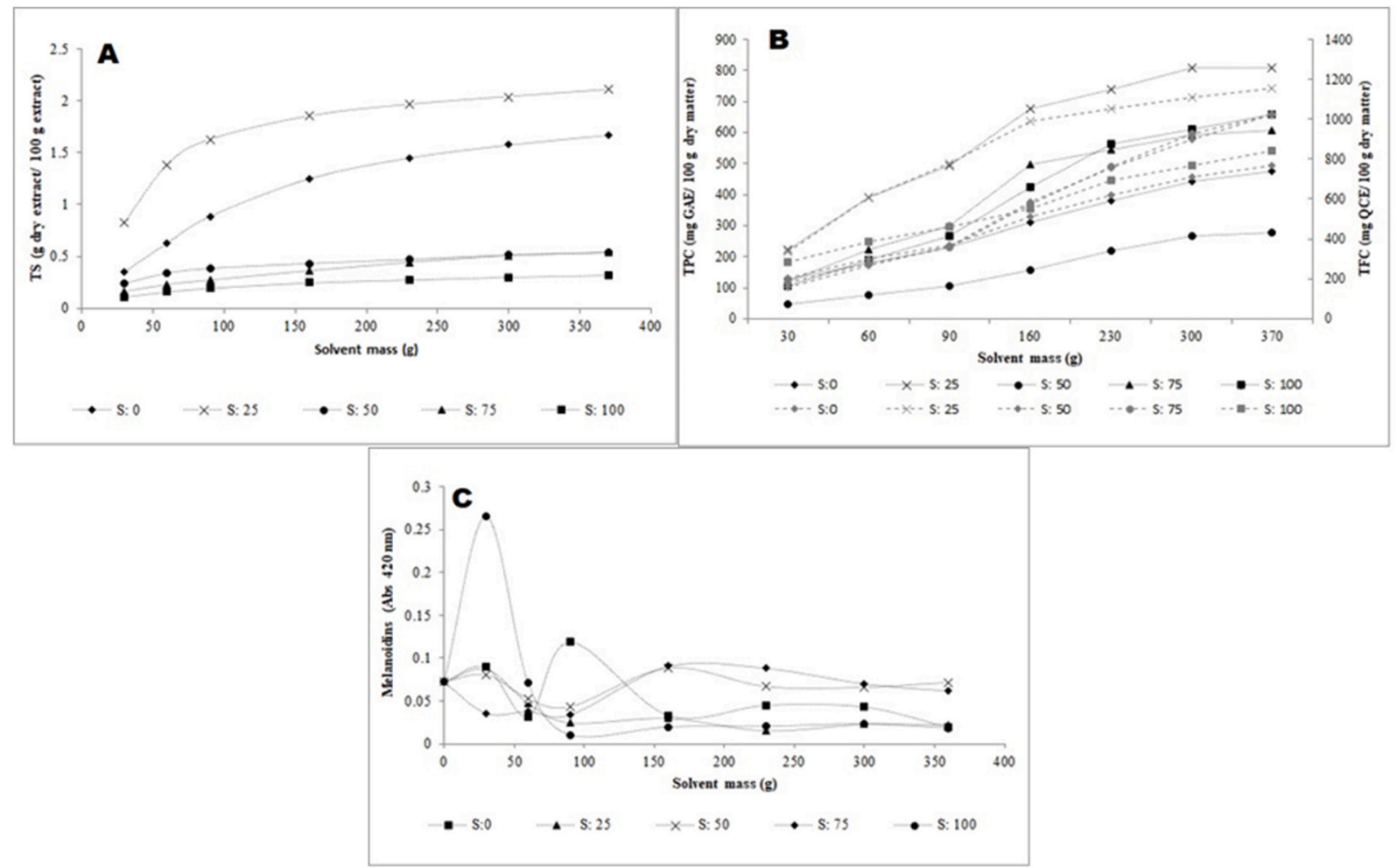

Fig. 5. Extraction yields as a function of time, curve predicted by the kinetic model.

Experimental values: points on the graph, values predicted by the kinetic model: dotted line. A- One-site model for phenols; B- Two-site model for phenols; C - One-site model for flavonoids; D- Two-site model for flavonoids.

the matrix to be extracted. The increase in temperature produced the greatest impact on the extraction and antioxidant activity of the extracts, not only because of the improvements in the diffusion of compounds in the matrix, but also because of the formation of new compounds with antioxidant activity derived from the non-enzymatic browning reactions (observed qualitatively by an increase in the brown color in the extracts). Finally, the content of alcohol as co-solvent is very dependent on the profile of antioxidant compounds in the matrix. In this case the best extracts were obtained with a $25 \%$ substitution, indicating a greater number of compounds of high and medium polarity. These data obtained at laboratory scale, could be used to extrapolate the process to industrial scale.

On the whole, the results of this study highlight an outstanding antioxidant potential of the subcritical fluid extraction of bioactive compounds from germinated quinoa grains, which ultimately encourages the use of these extracts for improving nutritive and healthbeneficial properties of food, cosmetic and pharmaceutical products.

To better understand the dynamics of the subcritical water extraction technique, it would be necessary to perform more detailed characterizations of the extracts, to evaluate not only a general extraction behavior but also the performance of compounds of interest, to make a correlation with their chemical properties and to identify the newly formed antioxidant compounds.

\section{CRediT authorship contribution statement}

Jesica R. Mufari: Conceptualization, Formal analysis, Methodology, Writing - original draft. Andrea C. Rodríguez-Ruiz: Formal analysis, Methodology, Writing - original draft. Antonella E. Bergesse: Data curation, interpreted the results and wrote the manuscript. Patricia P. Miranda-Villa: designed the experiment, interpreted the results and wrote the manuscript. Valeria Nepote: Writing - review \& editing. Alexis R. Velez: Funding acquisition, Supervision, Writing - review \& editing.

\section{Declaration of competing interest}

The authors declare that they have no known competing financial interests or personal relationships that could have appeared to influence the work reported in this paper.

\section{Acknowledgements}

The authors express their gratitude to Consejo Nacional de Investigaciones Científicas y Técnicas (CONICET) and Secretaría de Ciencia y Tecnología (SECyT) [grant number 30720130101068CB] for funding. To Universidad Nacional de Córdoba (UNC), ICTA, IMBIV, IIByT and IPQA for lending working spaces and offering available equipment used in this work.

\section{References}

Abderrahim, F., Huanatico, E., Repo-Carrasco-Valencia, R., Arribas, S., González, M., \& Condezo-Hoyos, L. (2012). Effect of germination on total phenolic compounds, total antioxidant capacity, Maillard reaction products and oxidative stress markers in cañihua (Chenopodium pallidicaule). Journal of Cereal Science, 56, 410-417. https:// doi.org/10.1016/j.jcs.2012.04.013

Abugoch James, L. E. (2009). Quinoa (Chenopodium quinoa Willd.): Composition, chemistry, nutritional, and functional properties. Advances in Food \& Nutrition Research, 58, 1-31. https://10.1016/S1043-4526(09)58001-1.

Alkhatib, A., Tsang, C., Tiss, A., Bahorun, T., Arefanian, H., Barake, R., \& Tuomilehto, J. (2017). Functional foods and lifestyle approaches for diabetes prevention and management. Nutrients, 9(12), 1310.

Anekpankul, T., Goto, M., Sasaki, M., Pavasant, P., \& Shotipruk, A. (2007). Extraction of anti-cancer damnacanthal from roots of Morinda citrifolia by subcritical water. Separation and Purification Technology, 55, 343-349. https://doi.org/10.1016/j. seppur.2007.01.004

Aoac International. (1999). Official methods of analysis of the association of official analysis chemist (16th ed.) 5th Revision. Gaithersburg, USA: AOAC International.

Atwaa, E. H., \& El-Araby, G. M. (2020). Effect of chia and quinoa seeds extract as natural antioxidant on the oxidative stability of fermented cream analogue. Journal of Food and Dairy Sciences, 11(2), 51-57. https://10.21608/JFDS.2020.78884. 
Benzie, I. F. F., \& Strain, J. J. (1996). The ferric reducing ability of plasma (FRAP) as a measure of "antioxidant power": The FRAP assay. Analytical Biochemistry, 70-76. https://doi.org/10.1006/abio.1996.0292

Bodoira, R., Rossi, Y., Montenegro, M., Maestri, D., \& Velez, A. (2017). Extraction of antioxidant polyphenolic compounds from peanut skin using water-ethanol at high pressure and temperature conditions. The Journal of Supercritical Fluids, 128, 57-65. https://doi.org/10.1016/j.supflu.2017.05.011

Bodoira, R., Velez, A., Andreatta, A., Martínez, M., \& Maestri, D. (2017). Extraction of bioactive compounds from sesame (Sesamum indicum L.) defatted seeds using water and ethanol under sub-critical conditions. Food Chemistry, 237, 114-120. https:// doi.org/10.1016/j.foodchem.2017.05.102

Bodoira, R., Velez, A., Rovetto, L., Ribotta, P., Maestri, D., \& Martínez, M. (2019). Subcritical fluid extraction of antioxidant phenolic compounds from pistachio (Pistacia vera L.) nuts: Experiments, modelling and optimization. Journal of Food Science, 84 (5), 963-970. https://doi.org/10.1111/1750-3841.14507

Carciochi, R. A. (2014). Obtención de ingredientes alimenticios con capacidad antioxidante mejorada por aplicación de distintos procesos a semillas de quinoa (Chenopodium quinoa) PhD Thesis. Argentina: Universidad de Buenos Aires. https://core.ac.uk/downloa d/pdf/148073156.pdf. (Accessed 30 September 2019).

Duba, K. S., Casazza, A. A., Mohamed, H. B., Perego, P., \& Fiori, L. (2015). Extraction of polyphenols from grape skins and defatted grape seeds using subcritical water: Experiments and modeling. Food and Bioproducts Processing, 94, 29-38. https://doi. org/10.1016/j.fbp.2015.01.001

Escribano, J., Cabanes, J., Jiménez-Atiénzar, M., Ibañez-Tremolada, M., GómezPando, L. R., García-Carmona, F., et al. (2017). Characterization of betalains, saponins and antioxidant power in differently colored quinoa (Chenopodium quinoa) varieties. Food Chemistry, 234, 285-294. https://doi.org/10.1016/j. foodchem.2017.04.187

Galanakis, C. M. (2012). Recovery of high added-value components from food wastes: Conventional, emerging technologies and commercialized applications. Trends in Food Science \& Technology, 26(2), 68-87.

Galanakis, C. M. (2018). Phenols recovered from olive mill wastewater as additives in meat products. Trends in Food Science \& Technology, 79, 98-105.

Gilbert-López, B., Plaza, M., Mendiola, J. A., Ibáñez, E., \& Herrero, M. (2017). Subcritical water extraction and neoformation of antioxidants. In G. H. Dominguez, \& M. J. Gonzalez (Eds.), Water Extraction of bioactive compounds from Plants to drug development (109-130). Netherlands: Elsevier. https://doi.org/10.1016/B978-0-12809380-1.00004-8.

Gong, Y., Zhang, X., He, L., Yan, Q., Yuan, F., \& Gao, Y. (2015). Optimization of subcritical water extraction parameters of antioxidant polyphenols from sea buckthorn (Hippophaë rhamnoides L.) seed residue. Journal of Food Science \& Technology, 52, 1534-1542. https://doi.org/10.1007/s13197-013-1115-7

Hata, S., Wiboonsirikul, J., Maeda, A., Kimura, Y., \& Adachi, S. (2008). Extraction of defatted rice bran by subcritical water treatment. Biochemical Engineering Journal, 40, 44-53. https://doi.org/10.1016/j.bej.2007.11.016

Herrero, M., Cifuentes, A., \& Ibáñez, E. (2006). Sub- and supercritical fluid extraction of functional ingredients from different natural sources: Plants, food-by-products, algae and microalgae. A review. Food Chemistry, 98, 136-148. https://doi.org/10.1016/j. foodchem.2005.05.058

Hodge, J. E. (1953). Chemistry of browning reactions in model systems. Journal of Agricultural and Food Chemistry, 1, 928-943.

Jokic, S., Gagic, T., Knez, Z., Šubaric, D., \& Škerget, M. (2018). Separation of active compounds from food by-product (cocoa shell) using subcritical water extraction. Molecules, 23, 1408.

Ko, M. J., Lee, J. H., Nam, H. H., \& Chung, M. S. (2017). Subcritical water extraction of phytochemicals from Phlomis umbrosa Turcz. Innovative Food Science \& Emerging Technologies, 42, 1-7. https://doi.org/10.1016/j.ifset.2017.05.009

Larrauri, M., Zunino, M. P., Zygadlo, J. A., Grosso, N. R., \& Nepote, V. (2016). Chemical characterization and antioxidant properties of fractions separated from extract of peanut skin derived from different industrial processes. Industrial Crops and Products, 94, 964-971. https://doi.org/10.1016/j.indcrop.2016.09.066

Laus, M. N., Gagliardi, A., Soccio, M., Flagella, Z., \& Pastore, D. (2012). Antioxidant activity of free and bound compounds in quinoa (Chenopodium quinoa Willd.) seeds in comparison with durum wheat and emmer. Journal of Food Science, 77(11), C1150-C1155. https://doi.org/10.1111/j.1750-3841.2012.02923.x
Leos-Rivas, C., Rivas-Morales, C., \& y García-Hernández, D. (2016). Actividad antioxidante y toxicidad. In C. Rivas-Morales, M. A. Oranday-Cardenas, \& M. J. Verde-Star (Eds.), Investigación en plantas de importancia médica (pp. 41-76). Barcelona: OmniaScience. https://doi.org/10.3926/oms.313.

Liu, J. (2019). Quinoa. In J. Wang, et al. (Eds.), Bioactive factors and processing technology for cereal foods (pp. 207-216). Singapore: Springer.

Mäkinen, O. E., Zannini, E., \& Arendt, E. K. (2013). Germination of oat and quinoa and evaluation of the malts as gluten free baking ingredients. Plant Foods for Human Nutrition, 68, 90-95. https://doi.org/10.1007/s11130-013-0335-3

Miranda-Villa, P. P., Mufari, J. R., Bergesse, A. E., \& Calandri, E. L. (2019). Effects of whole and malted quinoa flour addition on gluten-free muffins quality. Journal of Food Science, 84(1), 147-153. https://doi.org/10.1111/1750-3841.14413

M'hiri, N., Ioannou, I., Ghoul, M., \& Mihoubi-Boudhrioua, N. (2014). Extraction methods of citrus peel phenolic compounds. Food Reviews International, 30, 265-290. https:// doi.org/10.1080/87559129.2014.924139

Naga Sai Srujana, M., Anila Kumari, B., Uma Maheswari, K., Suneetha Devi, K. B., \& Jessie Suneetha, W. (2017). Sensory quality characteristics of gluten-free products prepared with germinated quinoa (Chenopodium quinoa wild). International Journal of Current Microbioogy and Applied Sciences, 6(8), 3507-3514. https://doi.org/ 10.20546/ijcmas.2017.607.419

Nickel, J., Spanier, L. P., Botelho, F. T., Gularte, M. A., \& Helbig, E. (2016). Effect of different types of processing on the total phenolic compound content, antioxidant capacity, and saponin content of Chenopodium quinoa Willd grains. Food Chemistry, 209, 139-143. https://doi.org/10.1016/j.foodchem.2016.04.031

Plaza, M., Amigo-Benavent, M., del Castillo, M. D., Ibáñez, E., \& Herrero, M. (2010). Facts about the formation of new antioxidants in natural samples after subcritical water extraction. Food Research International, 43, 2341-2348. https://doi.org/ 10.1016/j.foodres.2010.07.036

Quiroga, P. R., Riveros, C. G., Zygadlo, J. A., Grosso, N. R., \& Nepote, V. (2011). Antioxidant activity of essential oil of oregano species from Argentina in relation to their chemical composition. International Journal of Food Science and Technology, 46, 2648-2655. https://doi.org/10.1111/j.1365-2621.2011.02796.x

Re, R., Pellegrini, N., Proteggente, A., Pannala, A., Yang, M., \& Rice-Evans, C. (1999). Antioxidant activity applying an improved ABTS radical cation decolorization assay. Free Radical Biomedical Medicine, 26, 1231-1237. https://doi.org/10.1016/S08915849(98)00315-3

Rodríguez-Meizoso, I., Jaime, L., Santoyo, S., Señoráns, F., Cifuentes, A., \& Ibáñez, E. (2010). Subcritical wáter extraction and characterization of bioactive compounds from Haematocuccus pluvialis microalgo. Journal of Pharmaceutical and Biomedical Analysis, 51, 456-463. https://doi.org/10.1016/j.jpba.2009.03.014

Sobota, A., Świeca, M., Gęsiński, K., Wirkijowska, A., \& Bochnak, J. (2020). Yellowcoated quinoa (Chenopodium quinoa Willd)-physicochemical, nutritional, and antioxidant properties. Journal of the Science of Food and Agriculture, 100. https://doi. org/10.1002/jsfa.10222, 2035-2042.

Suárez-Estrella, D., Torri, L., Pagani, M. A., \& Marti, A. (2018). Quinoa bitterness: Causes and solutions for improving product acceptability. Journal of the Science of Food and Agriculture, 98(11), 4033-4041. https://doi.org/10.1002/jsfa.8980

Tomšik, A., Pavlić, B., Vladić, J., Cindrić, M., Jovanov, P., Sakač, M., et al. (2017). Subcritical water extraction of wild garlic (Allium ursinum L.) and process optimization by response surface methodology. The Journal of Supercritical Fluids, 128, 79-88. https://doi.org/10.1016/j.supflu.2017.05.012

Yammine, S., Delsart, C., Vitrac, X., Peuchot, M., \& Ghidossi, R. (2020). Characterisation of polyphenols and antioxidant potential of red and white pomace by-product extracts using subcritical water extraction. OENO One, 54(2), 263-278.

Yan, Z., Zhang, H., Sedem Dzah, C., Zhang, J., Diao, C., Ma, H., et al. (2020). Subcritical water extraction, identification, antioxidant and antiproliferative activity of polyphenols from lotus seedpod. Separation and Purification Technology, 236, 116217. https://doi.org/10.1016/j.seppur.2019.116217

Zeković, Z., Vidović, S., Vladić, J., Radosayljević, R., Cvejin, A., Elgndi, M. A., et al. (2014). Optimization of subcritical water extraction of antioxidants from Coriandrum sativum seeds by response surface methodology. The Journal of Supercritical Fluids, 95, 560-566. https://doi.org/10.1016/j.supflu.2014.09.004

Carciochi, R., Galván-D’Alessandro, L., Vandendriessche, P., \& Chollet, S. (2016). Effect of germination and fermentation process on the antioxidant compounds of quinoa seeds. Plant Foods for Human Nutrition, 71, 361-367. https://doi.org/10.1007/ s11130-016-0567-0 